\title{
EDITORIAL
}

\section{The changing role of mechanical ventilation in COPD}

\author{
J.M. Shneerson*
}

For many years, mechanical ventilation has been employed in patients with chronic obstructive pulmonary disease (COPD) but the recent development of noninvasive techniques, particularly nasal and face mask ventilation, have considerably increased its use. The enthusiasm for these methods, however, has not been matched by the results from well-constructed studies, and the role of ventilatory support both in acute and chronic respiratory failure is still not settled.

\section{Acute respiratory failure}

The steadily increasing number of publications on the use of noninvasive ventilation in acute infective exacerbations of COPD are hard to evaluate for several reasons. Firstly, most of the studies are uncontrolled or use historical or other unsatisfactory control groups. The definition of an infective exacerbation and its severity also varies considerably between the studies. Some studies compare the results of ventilation against "standard" medical treatment but this is frequently unspecified and, where details are given, oxygen appears to have been provided in flow rates sufficiently high to risk precipitating hypercapnia. Lastly, the criteria for the success or failure of noninvasive ventilation, such as the need for intubation, differ between studies.

Series published before the use of noninvasive ventilation indicated that the intubation rate was around $25 \%$ for hospitalized COPD patients with an acute infective exacerbation $[1,2]$. Their survival to discharge from hospital was around $60-75 \%$, and at 1 year was around $50 \%$ and 2 years around 35\% [3-6]. The major areas of interest with noninvasive techniques have been to show whether they can adequately ventilate these patients, reduce the intubation rate and improve survival. Approximately $60-80 \%$ of patients tolerate both positive pressure ventilation by face or nasal mask [7, 8] and negative pressure ventilation [9]. With mask ventilation, the arterial blood gases can usually be improved within 1-2 h, especially if the initial arterial carbon dioxide tension $\left(\mathrm{Pa}_{\mathrm{a}} \mathrm{CO}_{2}\right)$ is raised [10-16], although in a controlled study there was no difference in the blood gases between the ventilated and nonventilated patients [17]. Early studies with negative pressure ventilation also showed that ventilation could be adequately supported [18-22], and these findings have been confirmed in subsequent uncontrolled studies [9, 23-25]. The mechanisms by which noninvasive ventilation achieves these effects have not been established.

*Papworth Hospital, Papworth Everard, Cambridge CB3 8RE, UK.
It can reduce respiratory muscle activity [26] and increase maximum inspiratory pressures $[9,24]$, but whether these or any changes in respiratory drive or mechanics are clinically significant is still uncertain.

There are few data regarding the ability of negative pressure systems to avoid or delay intubation, but this question has been addressed in several reports of mask ventilation. Three series using historical controls suggested that the intubation rate could be reduced [27-29]. The results of a fourth are published in this edition of the Journal [30]. Patients were matched with a control group of 24 subjects selected from 72 who had been admitted during the previous 2 yrs. The matching criteria were age and $\mathrm{Pa}_{\mathrm{a}} \mathrm{CO}_{2}, \mathrm{pH}$ and Acute Physiology and Chronic Health Evaluation (APACHE) score on admission. The intubation rate was significantly less in the nasal ventilation group than in the historical controls (8 versus $38 \%)$, although the arterial oxygen tension $\left(\mathrm{Pa}, \mathrm{O}_{2}\right)$ and $P \mathrm{a}, \mathrm{CO}_{2}$ at discharge were similar in the two groups.

Two randomized, controlled studies have also investigated this problem. In one [31], only $9 \%$ of the patients treated by nasal ventilation required intubation, compared with $67 \%$ in the control group. The patients in this series were, however, highly selected from those that were eligible for the study and the high intubation rate in the control group also suggests that there may have been a bias in the patient's studied. No details about the inspired oxygen concentration or flow rate in the control group were given and it is possible that this precipitated the need for intubation in some of the patients. In the second study [32], 85 patients were randomized either to face mask ventilation or standard treatment, but the subjects were a selected group from the 275 who were eligible for the study. The most severely ill patients, for instance, were intubated initially and excluded from the study. This was also marred by the provision of up to $5 \mathrm{~L} \cdot \mathrm{min}^{-1}$ of oxygen in the standard treatment group in order to maintain the oxygen saturation above $90 \%$. This almost certainly precipitated hypercapnia in some patients and, thereby, increased the intubation rate, which was as high as $74 \%$. Intubation was required in only $26 \%$ of the group with face mask ventilation, which presumably protected many of these patients from oxygeninduced hypercapnia.

The results of all the controlled and uncontrolled studies suggest that face and nasal mask ventilation is associated with an intubation rate of $10-30 \%$, which is similar to the $25 \%$ recorded in the pre-mask ventilation era. This overall lack of detectable effect could be the result of mixing patients of different severities of respiratory failure 
in the series. Those with a severe acute illness, particularly if they are unconscious or have profuse secretions and a poor cough, would usually require intubation whether or not they are treated noninvasively initially, and those with a mild acute illness, whilst often tolerating mask ventilation [33], would avoid intubation whether or not they are ventilated noninvasively. The potential benefit of the new techniques is probably in the group of intermediate severity, where a mask or negative pressure system may adequately support ventilation until either the patient has improved clinically or clinical data, necessary to assist the decision whether or not to intubate, has been collected from sources such as relatives.

The survival rates using nasal ventilation have been the subject of three controlled studies. In two there was no difference between the mortality of the control and treated group [31, 32]. The other [34] was carried out in three centres, but patients with only mild respiratory failure $\left(P \mathrm{a}, \mathrm{CO}_{2}\right.$ greater than $6 \mathrm{kPa}$ and with only a mild acidosis) were entered. There was no difference in blood gases at $1 \mathrm{~h}$ after treatment or in the survival at 30 days between the ventilation and control groups on an "intention to treat" basis. The high $(30 \%)$ mortality in the conventionally treated group was ascribed to differences between the individual centres but may also have been related to the low intubation rate. There are no controlled series using negative pressure ventilation but in two reports of a large series of patients with severe acute respiratory failure $[25,35]$ the survival rate using tank ventilation ("iron lung") was as high as $90 \%$.

The provision of adequate ventilatory support whether noninvasively or with intubation should prevent death due to hypoxia, hypercapnia or acute respiratory acidosis but these are not the only causes of mortality in this group of patients. This also depends on the age, the overall performance status before the acute illness, the severity and duration of the infection, its response to treatment and any complications from the treatment. Noninvasive ventilation would only be expected to show a survival advantage over intubation if it either provides better respiratory support or is associated with fewer potentially fatal complications. Intubation usually requires sedation and immobilization, which increase the risk, for instance, of pneumonias and pulmonary emboli, but the chance of these complications may not nowadays be sufficiently large for any difference in survival rates to be apparent in studies of the size that have been carried out. Larger studies or those focusing on high risk patients, such as those who require prolonged ventilatory support because of difficulties in weaning, might show a survival difference.

The report in this edition of the Journal [30] found a higher survival rate at 6 and 12 months in patients who had received nasal ventilation during an episode of acute respiratory failure, even though the treatment after discharge from hospital was similar in the two groups. Whilst this could have been due to some, as yet unidentified, long-term benefit from short-term ventilatory support, it is more likely to reflect imperfect matching of the control and patient groups. Only the patient's age and markers of the severity of the acute illness were taken into account, whilst other determinants of long-term survival, such as the severity and progression of their airflow obstruction, were not allowed for.

Even if there is no survival advantage to using noninvasive ventilation, there could a financial advantage in avoiding the need for transfer to an Intensive Care Unit if intubation is not required. However, in the one report which has studied this [31], no difference in hospital charges was found and the use of face and nasal masks did not appear to reduce the length of hospital stay [31, 34], although this was documented in the study reported in this edition of the Journal [30]. The length of stay is determined mainly by the speed of resolution of the acute illness, this being independent of whether noninvasive or invasive ventilation is provided. Nasal ventilation has also been tried as an assistance in the weaning process of patients who require prolonged tracheostomy ventilation, but the results are inconclusive [36, 37]. This is hardly surprising, since the ability to provide partial and intermittent ventilatory support, whilst important, is only one element in the overall programme of care that is required to overcome weaning difficulties [38].

The data that are available do not allow firm recommendations to be made about the best techniques for ventilating these patients. Many subjects develop substantial leaks through the mouth when a nasal mask is used and require a face mask which encloses the mouth as well as the nose, despite its greater dead space. Of the negative pressure methods, tank ventilation appears to be more effective than the cuirass or jacket [39]. There are no adequate studies comparing positive and negative pressure systems and any differences between them may relate more to the sophistication of the ventilators than to whether positive or negative pressure is applied. All the negative pressure ventilators work in the controlled mode as pressure preset ventilators, whereas the positive pressure systems have a wider range of modes. No clear difference in the effectiveness of volume and pressure preset ventilation is apparent from the large number of uncontrolled studies or from two reports looking specifically at this question $[28,40]$. Use of positive expiratory pressure might be expected to reduce the work of triggering by overcoming intrinsic positive end-expiratory pressure (PEEP) and to be of benefit in those patients with obstructive sleep apnoeas, However, there is no evidence to support its routine use, especially since it may lead to hyperinflation and a fall in cardiac output. The expiratory flow limitation and instability of the respiratory pattern in COPD both during wakefulness and sleep, and particularly during acute infective exacerbations, require close attention to the details of the ventilator settings.

Regarding the duration of noninvasive ventilation, most studies have employed it for around $6 \mathrm{~h} \cdot \mathrm{day}^{-1}$ for 1-7 days, but it is not known whether this is optimal or what should determine the length of treatment. It would seem reasonable to continue until the $P \mathrm{a}, \mathrm{CO}_{2}$ has been normalized for about $24 \mathrm{~h}$ and until conventional medical treatment has begun to improve the underlying infection, but further studies are required. 


\section{Chronic respiratory failure}

The physiological changes during noninvasive ventilation in chronic stable COPD have been well-demonstrated but their clinical significance is uncertain. Nasal ventilation can improve the blood gases whilst patients are awake [41-43] and asleep [41, 44, 45], although two controlled studies have not shown any change [46, 47]. Controlled [48] and uncontrolled [49-52] studies with negative pressure ventilation have also demonstrated an improvement in blood gases during wakefulness.

The mechanisms by which the blood gases alter have not been established but are probably multifactorial. No increase in respiratory drive has been found [44] but this might improve either by relief of sleep deprivation or through a reduction in the cerebrospinal fluid bicarbonate concentration, which would increase the carbon dioxide sensitivity. Ventilatory support might also improve respiratory mechanics. It could alter the chest wall mobility and, thereby, increase its compliance. It could also increase lung compliance either by recruiting previously collapsed alveoli or by reducing lung water. There is no evidence for either of these, however, and the lack of improvement in spirometry [41] argues against these mechanisms being clinically significant.

The role of ventilation in improving respiratory muscle strength has been extensively investigated. Although no effect on maximal inspiratory and expiratory mouth pressures has been seen in prolonged studies $[46,47,53$, 54], an improvement in these pressures or a reduction of diaphragmatic electromyographic (EMG) activity has, with one exception [55], been documented in short-term studies with negative pressure systems [48, 49, 56-61], as well as a reduction in diaphragmatic activity with nasal ventilation [62]. The small changes in maximal mouth pressures may, however, have been due to alteration in the configuration of the chest wall or the length of the muscles rather than any change in the contractile properties of the muscles themselves.

The significance of any changes in respiratory muscle function is uncertain, particularly since respiratory muscle endurance appears to be only slightly increased if at all $[47,63]$. The question of whether chronic respiratory muscle fatigue was present and might be relieved by negative pressure ventilation was examined in the large Montreal study but this did not prove decisive because of problems with its design [64]. Firstly, the criterion for assessing the adequacy of ventilation was taken as a reduction of peak diaphragmatic EMG of more than 50\% but this was not validated in any way. The main outcome criterion was a change in the 6 min walking distance, which is, at best, only indirectly related to any change in respiratory muscle fatigue. Lastly, the patients only used the treatment for a mean of $2.5 \mathrm{~h} \cdot$ day $^{-1}$ and this was mainly while they were awake rather than asleep. The negative finding of this study does not, therefore, provide evidence either way concerning the role or relief of respiratory muscle fatigue.

It is hard to predict on theoretical grounds what effect these physiological changes might have on the survival of patients with chronic stable COPD, since the causes of death other than during an acute infective exacerbation have not been well identified. A poor prognosis is associated with severe and rapidly progressing airflow obstruction $[65,66]$ but this is probably unaffected by ventilatory support. It is the patients whose $P \mathrm{a}, \mathrm{CO}_{2}$ is persistently elevated without any acute exacerbation, and those in whom it remains elevated after an acute exacerbation (60\%) [67], who are least likely to tolerate longterm oxygen treatment without worsening of hypercapnia. In these subjects, domiciliary ventilatory support needs to be considered in order to relieve symptoms and complications, and to improve the prognosis.

Two large series have examined long-term survival in COPD using tracheostomy ventilation. The first [68] reviewed 50 subjects treated with $11-17 \mathrm{~h}$ ventilation per day, but little blood gas and no sleep study data are available to evaluate its efficacy. The survival rates were 88 , $72,54,34$ and $18 \%$ at $1-5$ yrs, respectively. Slightly better results have been reported recently [69] in an Association Nationale pour le Traitement a Domicile de l'Insuffisance Respiratoire (ANTADIR) multicentre French trial, which included 259 patients, although $24 \%$ of these did not require any ventilation through their tracheostomy. The majority of these were also receiving longterm oxygen therapy (LTOT). The 2, 3, 5 and 10 year survival rates were $70,60,44$ and $20 \%$, respectively, for the whole series but only 56,41 and $22 \%$ at 3,5 and 10 yrs, respectively, for the ventilated patients. A better prognosis was associated with an age of less than $65 \mathrm{yrs}$, use of an uncuffed tracheostomy tube and $\mathrm{Pa}_{\mathrm{a}} \mathrm{O}_{2}$ greater than $7.3 \mathrm{kPa}(55 \mathrm{mmHg}) 3$ months after the tracheostomy was performed.

A recent study of 33 COPD patients using nasal ventilation, some of whom also received oxygen treatment, showed the 1, 3 and 5 year probabilities of still using nasal intermittent positive pressure ventilation (NIPPV) to be approximately 85,75 and 43 , respectively [70]. At 1 year, the $P \mathrm{a}, \mathrm{O}_{2}$ had risen by $0.8 \mathrm{kPa}$ and the $P \mathrm{a}, \mathrm{CO}_{2}$ had fallen by $1.9 \mathrm{kPa}$. The results of this study and the two tracheostomy studies do not show any significant differences from those of the Nocturnal Oxygen Therapy Trial (NOTT) and Medical Research Council (MRC) trial of long-term oxygen therapy using 12-24 h of oxygen per day [71, 72]. Accurate comparisons between the studies are impossible, however, since it is not known whether the patients were started on oxygen and mechanical ventilation at a similar stage in their natural history and none of the studies controlled for smoking, which may be a more important factor affecting survival than either of the treatments.

The lack of difference between the survival rates has led to the use of the combination of nasal ventilation and oxygen. A randomized controlled study [73] showed that the daytime $P \mathrm{a}, \mathrm{O}_{2}$ and $\mathrm{Pa}, \mathrm{CO}_{2}$ and night-time $\mathrm{Pa}, \mathrm{CO}_{2}$ were improved with bi-level pressure support plus oxygen, compared with oxygen alone but, unfortunately, the oxygen was given at a standard rate of $2 \mathrm{~L} \cdot \mathrm{min}^{-1}$ and not individually optimized. The $\mathrm{Pa}, \mathrm{CO}_{2}$ in the oxygen only group may, therefore, have been iatrogenically raised, so that this study does not show whether ventilation with oxygen is any better than no treatment alone. In 
addition, patients with more than five apnoeas $\cdot \mathrm{h}^{-1}$ were excluded from the study because of lack of a back-up rate on the ventilator. In a separate study of 50 COPD patients [74], who all received long-term oxygen as well as nasal ventilation, approximately $70 \%$ were still using the ventilator at $1 \mathrm{yr}$ and $56 \%$ at $2 \mathrm{yrs}$. The only physiological change was a reduction in the $\mathrm{Pa}_{\mathrm{a}} \mathrm{CO}_{2}$ at 1 and 2 yrs. These figures, which approximate to the survival rate, are not significantly different from the large studies of ventilation without oxygen or the NOTT and MRC LTOT series.

There results suggest that either mechanical ventilation provides very little, if any, survival advantage or that it only improves the prognosis in a subgroup of COPD patients and that death in the other is related to changes, such as progression of airflow obstruction or cardiac dysfunction, which are not improved by mechanical ventilation. More selective use of ventilation in patients with hypoxia- or hypercapnia-related complications, or in those who are at risk of developing these, might prove more effective. It would also seem prudent to give supplemental oxygen to those in whom hypoxia persists despite normalization of the $\mathrm{Pa}, \mathrm{CO}_{2}$ with ventilation. It is not known whether pressure preset ventilation might be more effective than volume preset ventilation used in the assist-control mode as in most of the large studies $[70,74]$. A single short-term study during wakefulness did not show any significant differences between the two techniques [43].

A separate indication for long-term ventilation is to try to improve the quality of life, or reduce the symptoms in patients with COPD. No improvement in exercise ability was found in the only controlled study to examine this [46], although these patients did show an improvement in neuropsychiatric function. There are few other quality of life data available. In one study, patients with nasal ventilation had a reasonable quality of life but no measurements were made before treatment to examine its effect [70]. In another report, there was no overall change in quality of life when nasal ventilation was compared with LTOT, but symptom relief was improved [73]. Ventilation might not be expected to significantly alter, for instance, exertional breathlessness, which is more closely related to the severity of airflow obstruction, but it could improve symptoms that result primarily from sleep disruption due to respiratory problems. The total sleep time and the sleep efficiency are improved with nasal ventilation, although sleep architecture and the number of arousals are unchanged, both without [44] and with [73] added oxygen. Further studies of quality of life looking both at the benefits and the intrusiveness of the ventilator are required. Compliance with long-term ventilation is likely to be poor even if it improves ventilation, unless it results in symptomatic benefit or an overall improvement in the quality of life [53].

\section{The future}

The evidence regarding the use of ventilatory support that is available suggests that it should be used selectively both during acute infective exacerbations and in the chronic stable phase of chronic obstructive pulmonary disease. Its indications should be guided by an understanding of the possible mechanisms by which it might work. In the acute situation, for instance, it is likely to provide most benefit in patients of intermediate severity and those who are able to tolerate either a mask or tank ventilator, whereas in the stable patient it should be targeted at those whose symptoms, quality of life, complications or prognosis are related to hypoxia, hypercapnia or to sleep disruption, and in whom maximum medical treatment has already been instituted. If hypoxia cannot be corrected by ventilation alone, despite the arterial carbon dioxide tension being normal, supplemental oxygen should be considered.

\section{References}

1. Kettel LJ, Diener CF, Morse JO, Stein HF, Burrows B. Treatment of acute respiratory acidosis in chronic obstructive lung disease. JAMA 1971; 217: 1503-1508.

2. Bone RC, Pierce AK, Johnson RL. Controlled oxygen administration in acute respiratory failure in chronic obstructive pulmonary disease: a reappraisal. Am J Med 1978; 65: 896-902.

3. Gottlieb LS, Balchurn OJ. Course of chronic obstructive pulmonary disease following first onset of respiratory failure. Chest 1973; 63: 5-8.

4. Martin TR, Lewis SW, Albert RK. The prognosis of patients with chronic obstructive pulmonary disease after hospitalization for acute respiratory failure. Chest 1982; 82: 310-318.

5. Morganroth ML, Morganroth JL, Nett LM, Petty TL. Criteria for weaning from prolonged mechanical ventilation. Arch Intern Med 1984; 144: 1012-1016.

6. Witck TJ, Schachter EN, Dean NL, Beck GJ. Mechanically-assisted ventilation in a community hospital: immediate outcome, hospital charges, and follow-up of patients. Arch Intern Med 1985; 145: 235-239.

7. Benhamou D, Girault C, Faure C, Portier F, Muir J-F. Nasal mask ventilation in acute respiratory failure. Chest 1992; 102: 912-917.

8. Confalonieri M, Aiolfi S, Gandola L, Scartabellati A, Della Porta R, Parigi P. Severe exacerbations of chronic obstructive pulmonary disease treated with BiPAP by nasal mask. Respiration 1994; 61: 310-316.

9. Montserrat JM, Martos JA, Alarcon A, Celis R, Plaza V, Picado C. Effect of negative pressure ventilation on arterial blood gas pressures and inspiratory muscle strength during an exacerbation of chronic obstructive lung disease. Thorax 1991; 46: 6-8.

10. Meduri GU, Conoscenti CC, Menashe P, Nair S. Noninvasive face mask ventilation in patients with acute respiratory failure. Chest 1989; 95: 865-870.

11. Elliott MW, Steven MH, Phillips GD, Branthwaite MA. Non-invasive mechanical ventilation for acute respiratory failure. BMJ 1990; 300: 358-360.

12. Chevrolet J-C, Jolliet P, Abajo B, Toussi A, Louis M. Nasal positive pressure ventilation in patients with acute respiratory failure: difficult and time-consuming procedure for nurses. Chest 1991; 100: 775-782.

13. Meduri GU, Abou-Shala N, Fox RC, Jones CB, Leeper $\mathrm{KV}$, Wunderink RG. Noninvasive face mask mechanical ventilation in patients with acute hypercapnic respiratory failure. Chest 1991; 10: 445-454. 
14. Marino W. Intermittent volume cycled mechanical ventilation via nasal mask in patients with respiratory failure due to COPD. Chest 1991; 99: 681-684.

15. Fernandez R, Blanch L, Valles J, Baigorri F, Artigas A. Pressure support ventilation via face mask in acute respiratory failure in hypercapnic COPD patients. Intensive Care Med 1993; 19: 456-461.

16. Wysocki M, Tric L, Wolff MA, Gertner J, Millet H, Herman B. Noninvasive pressure support ventilation in patients with acute respiratory failure. Chest 1993; 103: 907-913.

17. Foglio C, Vitacca M, Quadri A, Scalvini S, Marangoni $\mathrm{S}$, Ambrosino N. Acute exacerbations in severe COLD patients: treatment using positive pressure ventilation by nasal mask. Chest 1992; 101: 1533-1538.

18. Boutourline-Young HJ, Whittenberger JL. The use of artificial respiration in pulmonary emphysema accompanied by high carbon dioxide levels. J Clin Invest 1951; 30: 838-847.

19. Stone DJ, Schwartz A, Newman W, Feltman JA, Lovelock FJ. Precipitation by pulmonary infection of acute anoxia, cardiac failure and respiratory acidosis in chronic pulmonary disease: Pathogenesis and treatment. Am J Med 1953; 14: 14-22.

20. Lovejoy FW, Yu PNG, Nye RE, Joos HA, Simpson JH. Pulmonary hypertension. 111. Physiologic studies in three cases of carbon dioxide narcosis treated by artificial respiration. Am J Med 1954; 16: 4-11.

21. Westlake EK, Simpson T, Kaye M. Carbon dioxide narcosis in emphysema. Q J Med 1955; 24: 155-173.

22. Sieker HO, Hickam JB. Carbon dioxide intoxication: the clinical syndrome, its etiology and management with particular reference to the use of mechanical respirators. Medicine 1956; 35: 389-423.

23. Sauret JM, Guitart AC, Rodriquez-Frojan G, Cornudella $\mathrm{R}$. Intermittent short-term negative pressure ventilation and increased oxygenation in COPD patients with severe hypercapnic respiratory failure. Chest 1991; 100: 150-158.

24. Corrado A, Bruscoli G, De Paola E, Ciardi-Dupre GF, Baccini A, Taddei M. Respiratory muscle insufficiency in acute respiratory failure of subjects with severe COPD: treatment with intermittent negative pressure ventilation. Eur Respir J 1990; 3: 644-648.

25. Corrado A, Bruscoli G, Messori A, et al. Iron lung treatment of subjects with COPD in acute respiratory failure: evaluation of short- and long-term prognosis. Chest 1992; 101: 692-696.

26. Carrey Z, Gottfried SB, Levy RD. Ventilatory muscle support in respiratory failure with nasal positive pressure ventilation. Chest 1990; 97: 150-158.

27. Brochard L, Isabey D, Piquet J, et al. Reversal of acute exacerbations of chronic obstructive lung disease by inspiratory assistance with a face mask. N Engl J Med 1990; 323: $1523-1530$

28. Vitacca M, Rubini F, Foglio K, Scalvini S, Nava S, Ambrosino N. Non-invasive modalities of positive pressure ventilation improve the outcome of acute exacerbations in COLD patients. Intensive Care Med 1993; 19: 450-455.

29. Foglio K, Clini E, Vitacca M. Different modes of noninvasive intermittent positive pressure ventilation (IPPV) in acute exacerbations of COLD patients. Monaldi Arch Chest Dis 1994; 49: 556-557.

30. Confalonieri M, Parigi P, Scartabellati A, et al. Noninvasive mechanical ventilation improves the immediate and longterm outcome of COPD patients with acute respiratory failure. Eur Respir J 1996; 9: 422-430.
31. Kramer N, Meyer TJ, Meharg J, Cece RD, Hill NS. Randomized prospective trial of noninvasive positive pressure ventilation in acute respiratory failure. Am $J$ Respir Crit Care Med 1995; 151: 1799-1806.

32. Brochard L, Mancebo J, Wysocki M, et al. Noninvasive ventilation for acute exacerbations of chronic obstructive pulmonary disease. N Engl J Med 1995; 333: 817-822.

33. Ambrosino N, Foglio K, Rubini F, Clini E, Nava S, Vitacca M. Non-invasive mechanical ventilation in acute respiratory failure due to chronic obstructive pulmonary disease: correlates for success. Thorax 1995; 50: 755-757.

34. Bott J, Carroll MP, Conway JH, et al. Randomised controlled trial of nasal ventilation in acute ventilatory failure due to chronic obstructive airways disease. Lancet 1993; 341: 1555-1557.

35. Corrado A, Gorini M, De Paola E, et al. Iron lung treatment of acute on chronic respiratory failure: 16 years of experience. Monaldi Arch Chest Dis 1994; 49: 552-555.

36. Udwadia ZF, Santis GK, Steven MH, Simonds AK. Nasal ventilation to facilitate weaning in patients with chronic respiratory insufficiency. Thorax 1992; 47: 715- 718 .

37. Restrick LJ, Scott AD, Ward EM, Feneck RO, Cornwell WE, Wedzicha JA. Nasal intermittent positive-pressure ventilation in weaning intubated patients with chronic respiratory disease from assisted intermittent, positivepressure ventilation. Respir Med 1993; 87: 199-204.

38. Smith IE, Shneerson JM. A progressive care programme for prolonged ventilatory failure: analysis of outcome. Br J Anaesth 1995; 75: 399-404.

39. Jameson AG, Ferrer MI, Harvey RM. Some effects of mechanical respirators upon respiratory gas exchange and ventilation in chronic pulmonary emphysema. Am Rev Respir Dis 1959; 80: 510-521.

40. Meecham Jones DJ, Paul EA, Grahame-Clarke C, Wedzicha JA. Nasal ventilation in acute exacerbations of chronic obstructive pulmonary disease: effect of ventilator mode on arterial blood gas tensions. Thorax 1994; 49: 1222-1224.

41. Carroll N, Branthwaite MA. Control of nocturnal hypoventilation by nasal intermittent positive pressure ventilation. Thorax 1988; 43: 349-353.

42. Elliott MW, Mulvey DA, Moxham J, Green M, Branthwaite MA. Domiciliary nocturnal nasal intermittent positive pressure ventilation in COPD: mechanisms underlying changes in arterial blood gas tensions. Eur Respir $J$ 1991; 4: 1044-1052.

43. Meecham Jones DJ, Wedzicha JA. Comparison of pressure and volume preset nasal ventilator systems in stable chronic respiratory failure. Eur Respir J 1993; 6: 10601064.

44. Elliott MW, Simonds AK, Carroll MP, Wedzicha JA, Branthwaite MA. Domiciliary nocturnal nasal intermittent positive pressure ventilation in hypercapnic respiratory failure due to chronic obstructive lung disease: effects on sleep and quality of life. Thorax 1992; 47: 342-348.

45. Restrick LJ, Fox NC, Braid G, Ward EM, Paul EA, Wedzicha JA. Comparison of nasal pressure support ventilation with nasal intermittent positive pressure ventilation in patients with nocturnal hypoventilation. Eur Respir J 1993; 6: 364-370.

46. Strumpf DA, Millman RP, Carlisle CC, et al. Nocturnal positive-pressure ventilation via nasal mask in patients with severe chronic obstructive pulmonary disease. Am Rev Respir Dis 1991; 144: 1234-1239.

47. Renston JP, DiMarco AF, Supinski GS. Respiratory muscle rest using nasal BiPAP ventilation in patients with stable severe COPD. Chest 1994; 105: 1053-1060.

48. Cropp A, DiMarco AF. Effects of intermittent negative 
pressure ventilation on respiratory muscle function in patients with severe chronic obstructive pulmonary disease. Am Rev Respir Dis 1987; 135: 1056-1061.

49. Rodenstein DO, Stanescu DC, Cultita G, Liistro G, Veriter C. Ventilatory and diaphragmatic EMG responses to negative-pressure ventilation in airflow obstruction. $J$ Appl Physiol 1988; 65: 1621-1626.

50. Fernandez E, Weiner P, Meltzer E, Lutz MM, Badish DB, Cherniack RM. Sustained improvement in gas exchange after negative pressure ventilation for 8 hours per day on 2 successive days in chronic airflow limitation. Am Rev Respir Dis 1991; 144: 390-394.

51. Gutierrez M, Beroiza T, Contreras G, et al. Weekly cuirass ventilation improves blood gases and inspiratory muscle strength in patients with chronic airflow limitation and hypercarbia. Am Rev Respir Dis 1988; 138: 617-623.

52. Cooper GB, Harris ND, Howard P. Acute effects of external negative pressure ventilation in chronic obstructive pulmonary disease compared with normal subjects. Eur Respir J 1991; 4: 63-68.

53. Zibrak JD, Hill NS, Federman EC, Kwa SL, O'Donnell C. Evaluation of intermittent long-term negative-pressure ventilation in patients with severe chronic obstructive pulmonary disease. Am Rev Respir Dis 1988; 138: $1515-1518$.

54. Celli B, Lee H, Criner G, Bermudez M, et al. Controlled trial of external negative pressure ventilation in patients with severe chronic airflow obstruction. Am Rev Respir Dis 1989; 140: 1251-1256.

55. Lien T-C, Wang J-H, Chang M-T, Kuo C-D. Comparison of BiPAP nasal ventilation and ventilation via iron lung in severe stable COPD. Chest 1993; 104: 460-466.

56. Rochester DF, Braun NMT, Laine S. Diaphragmatic energy expenditure in chronic respiratory failure: the effect of assisted ventilation with body respirators. Am J Med 1977; 63: 223-232.

57. Ambrosino N, Montagna T, Nava S, et al. Short-term effect of intermittent negative pressure ventilation in COPD patients with respiratory failure. Eur Respir $J$ 1990; 3: 502-508.

58. Belman MJ, Soo Hoo GW, Kuci JH, Shadmehr R. Efficacy of positive $v s$ negative pressure ventilation in unloading the respiratory muscles. Chest 1990; 98: 850-856.

59. Nava S, Ambrosino N, Zocchi L, Rampulla C. Diaphragmatic rest during negative pressure ventilation by Pneumowrap: assessment in normal and COPD patients. Chest 1990; 98: 857-865.

60. Scano G, Gigliotti F, Duranti R, Spinelli A, Gorini M, Schiavina M. Changes in ventilatory muscle function with negative pressure ventilation in patients with severe COPD. Chest 1990; 97: 322-327.

61. Gigliotti F, Duranti R, Fabiani A, Schiavina M, Scano
G. Suppression of ventilatory muscle activity in healthy subjects and COPD patients with negative pressure ventilation. Chest 1991; 99: 1186-1192.

62. Ambrosino N, Nava S, Bertone P, Fracchia C, Rampulla C. Physiologic evaluation of pressure support ventilation by nasal mask in patients with stable COPD. Chest 1992; 101: 385-391.

63. Levine S, Levy SF, Henson DJ. Effect of negative pressure ventilation on ventilatory muscle endurance in patients with severe chronic obstructive pulmonary disease. Am Rev Respir Dis 1992; 146: 722-729.

64. Shapiro SH, Ernst P, Gray-Donald K, et al. Effect of negative pressure ventilation in severe chronic obstructive pulmonary disease. Lancet 1992; 340: 1425-1429.

65. Anthonisen NR, Wright EC, Hodgkin JE. Prognosis in chronic obstructive pulmonary disease. Am Rev Respir Dis 1986; 133: 14-20.

66. Portier F, Defouilloy C, Muir J-F. Determinants of immediate survival among chronic respiratory insufficiency patients admitted to an intensive care unit for acute respiratory failure: a prospective multicenter study. Chest 1992; 101: 204-210.

67. McNally E, Fitzpatrick M, Bourke S, Costello R, McNicholas WT. Reversible hypercapnia in acute exacerbations of chronic obstructive pulmonary disease (COPD). Eur Respir J 1993; 6: 1353-1356.

68. Robert D, Gerard M, Leger P, et al. La ventilation mecanique a domicile definitive par tracheotomie de l'insuffisant respiratoire chronique. Rev Fr Mal Respir 1983; 11: 923-936.

69. Muir J-F, Girault C, Cardinaud J-P, Polu J-M. Survival and long-term follow-up of tracheostomized patients with COPD treated by home mechanical ventilation: a multicenter French study in 259 patients. Chest 1994; 106: 201-209.

70. Simonds AK, Elliott MW. Outcome of domiciliary nasal intermittent positive pressure ventilation in restrictive and obstructive disorders. Thorax 1995; 50: 604-609.

71. Nocturnal Oxygen Therapy Trial Group. Continuous or nocturnal oxygen therapy in hypoxemic chronic obstructive lung disease. Ann Intern Med 1980; 93: 391-398.

72. Report of the Medical Research Council Working Party. Long-term domiciliary oxygen therapy in chronic hypoxic cor pulmonale complicating chronic bronchitis and emphysema. Lancet 1981; i: 681-685.

73. Meecham Jones DJ, Paul EA, Jones PW, Wedzicha JA. Nasal pressure support ventilation plus oxygen compared with oxygen therapy alone in hypercapnic COPD. Am J Respir Crit Care Med 1995; 152: 538-544.

74. Leger P, Bedicam JM, Cornette A, et al. Nasal intermittent positive pressure ventilation: long-term followup in patients with severe chronic respiratory insufficiency. Chest 1994; 105: 100-105. 